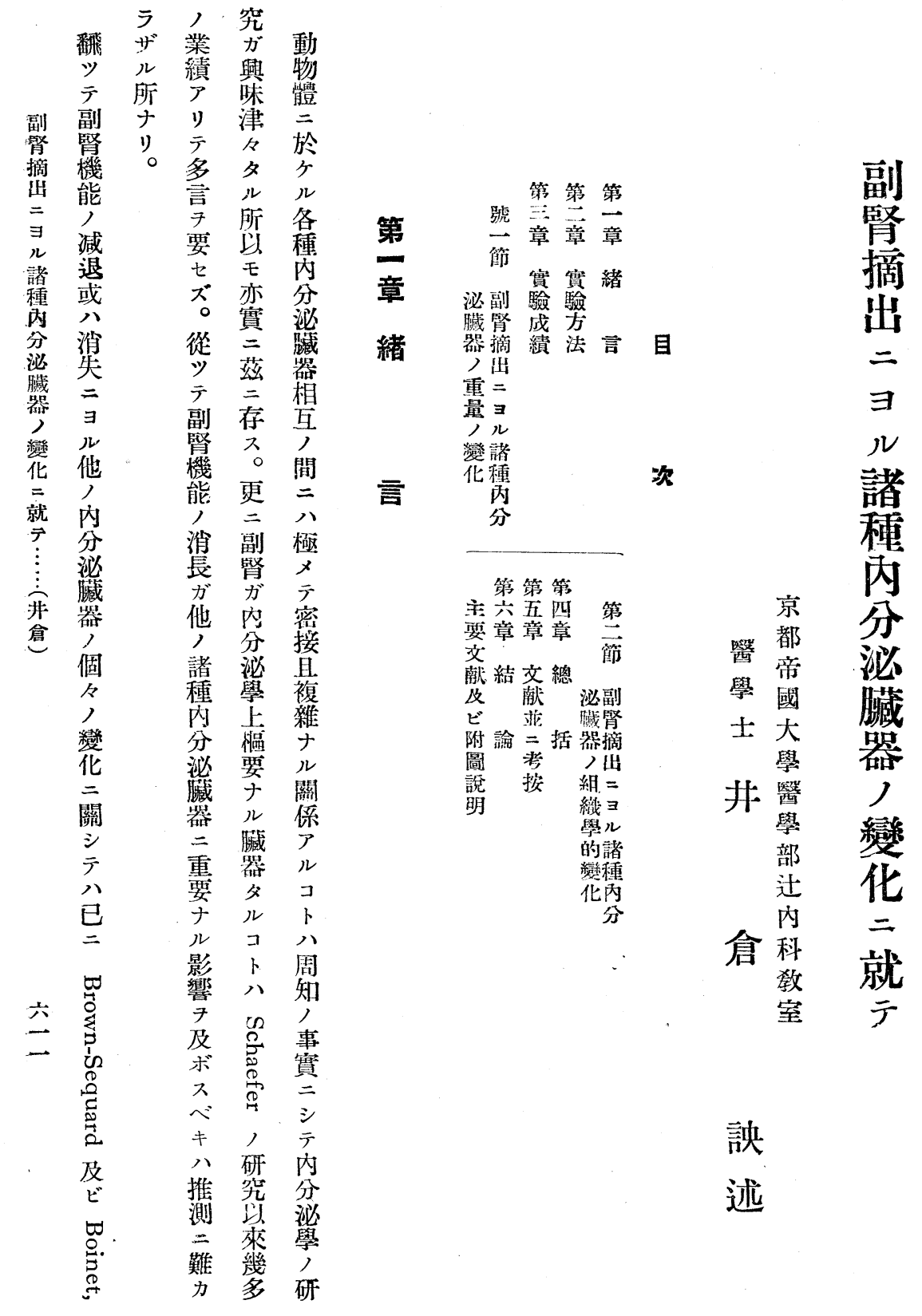



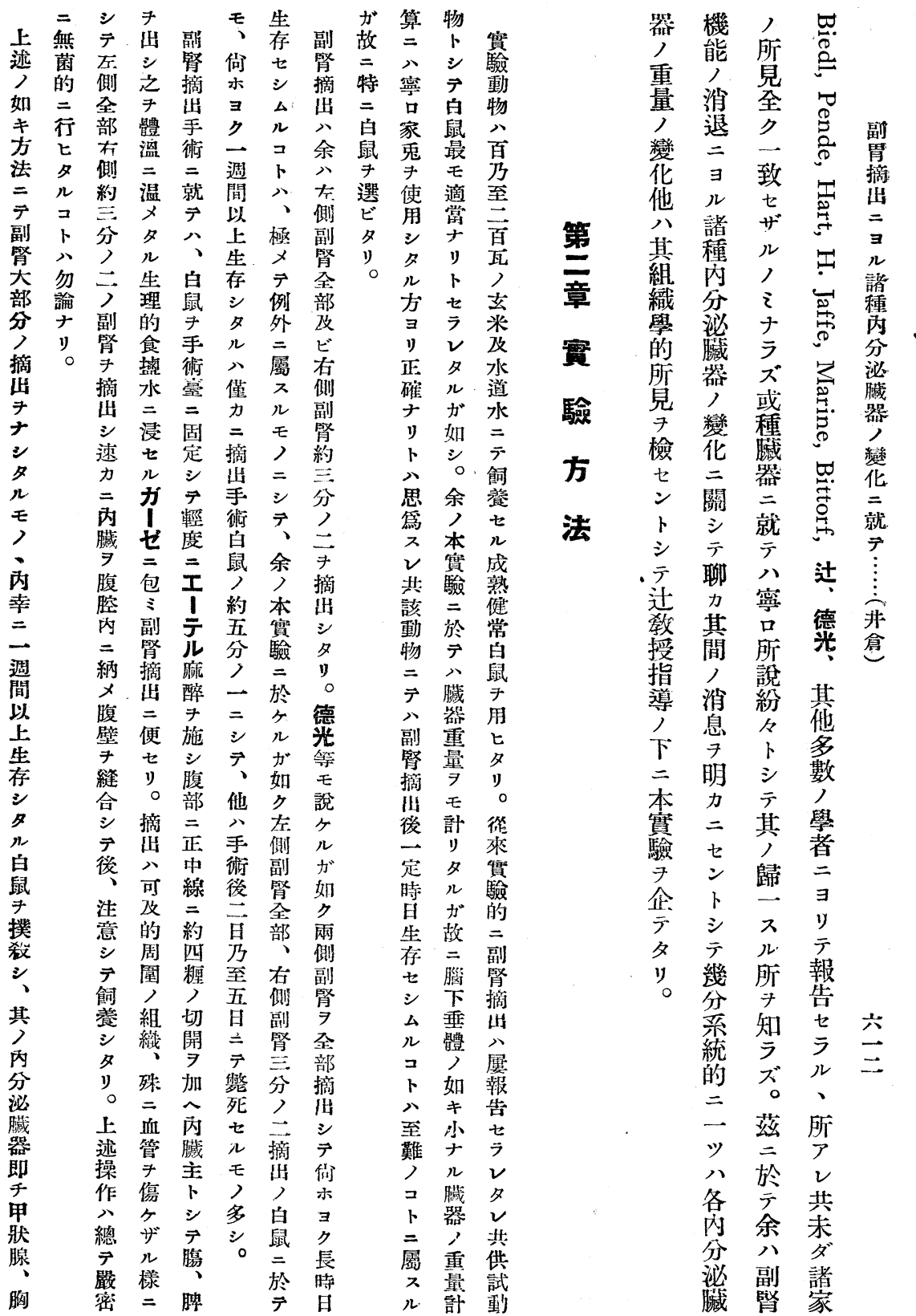
第 一 表

\begin{tabular}{|c|c|c|c|c|c|c|c|}
\hline $\begin{array}{l}\text { 白番 } \\
\text { 鼠號 }\end{array}$ & $\begin{array}{l}\text { 體 } \\
\text { 重 }\end{array}$ & $\begin{array}{l}\text { 甲 } \\
\text { 牀 } \\
\text { 腺 }\end{array}$ & $\begin{array}{l}\text { 胸 } \\
\text { 腺 }\end{array}$ & $\begin{array}{l}\text { 搭 } \\
\text { 臟 }\end{array}$ & $\begin{array}{l}\text { 睪 } \\
\text { 如 }\end{array}$ & $\begin{array}{l}\text { 卵 } \\
\text { 巢 }\end{array}$ & $\begin{array}{l}\text { 㬵垂 } \\
\text { 下體 }\end{array}$ \\
\hline (1) & 165 & 0.016 & 0.186 & 0.727 & 1.555 & & 0.005 \\
\hline (口) & 182 & 0.018 & 0.110 & 0.735 & 1.415 & & 0.006 \\
\hline (>) & 180 & 0.017 & 0.180 & 0.750 & 1.892 & • & 0.005 \\
\hline$(=)$ & 132 & 0.013 & 0.183 & 0.709 & 1.755 & & 0.005 \\
\hline (ホ) & 152 & 0.017 & 0.195 & 6.710 & 1.796 & & 0.006 \\
\hline$(へ)$ & 145 & 0.015 & 0.190 & 0.718 & & 0.062 & 0.004 \\
\hline (ト) & 155 & 0.015 & 0.185 & 0.720 & & 0.063 & 0.005 \\
\hline (f) & 172 & 0.018 & 0.165 & 0.718 & & 0.052 & 0.006 \\
\hline (y) & 150 & 0.016 & 0.187 & 0.719 & & 0.050 & 0.005 \\
\hline (x) & 142 & 0.014 & 0.166 & 0.698 & & 0.058 & 0.006 \\
\hline 平均 & 157.5 & 0.0159 & 0.1747 & 0.7204 & 1.6706 & 0.057 & 0.0053 \\
\hline 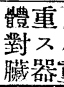 & $\begin{array}{l}\text { 良二 } \\
\text { 华均 }\end{array}$ & 0.0101 & $0.110 \mathrm{~s}$ & 0.4574 & 1.0406 & 0.0873 & 0.0024 \\
\hline
\end{tabular}
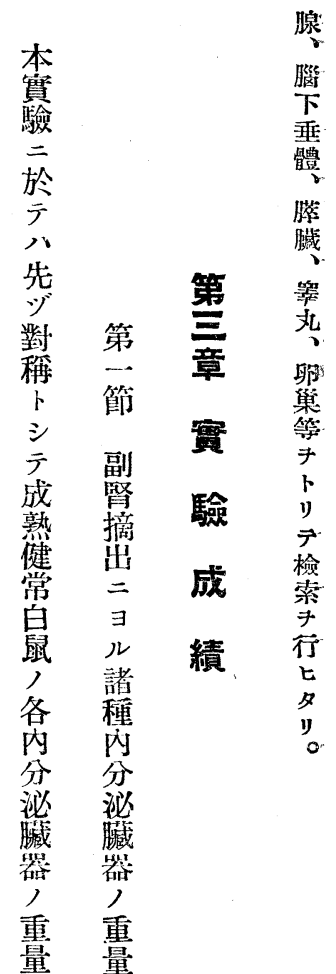

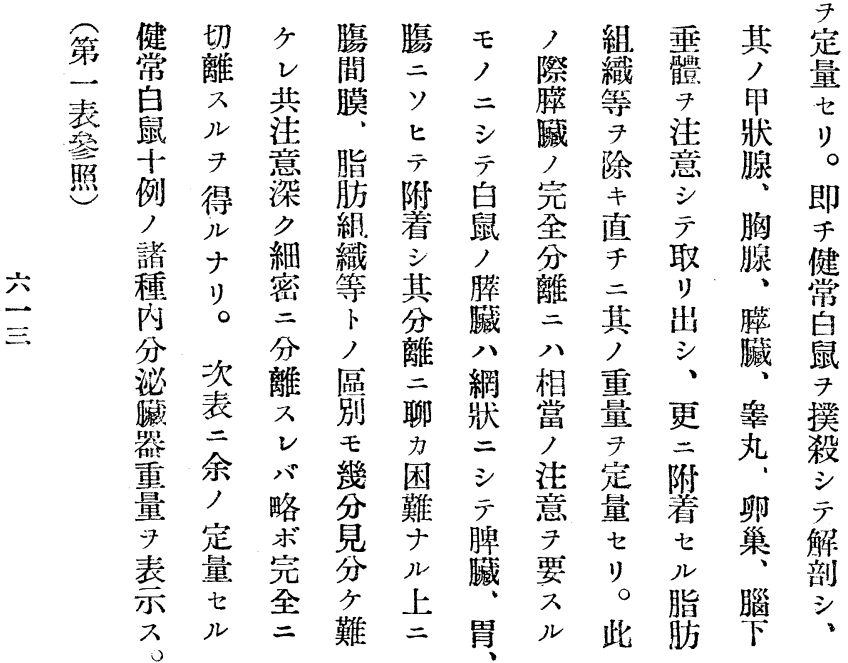




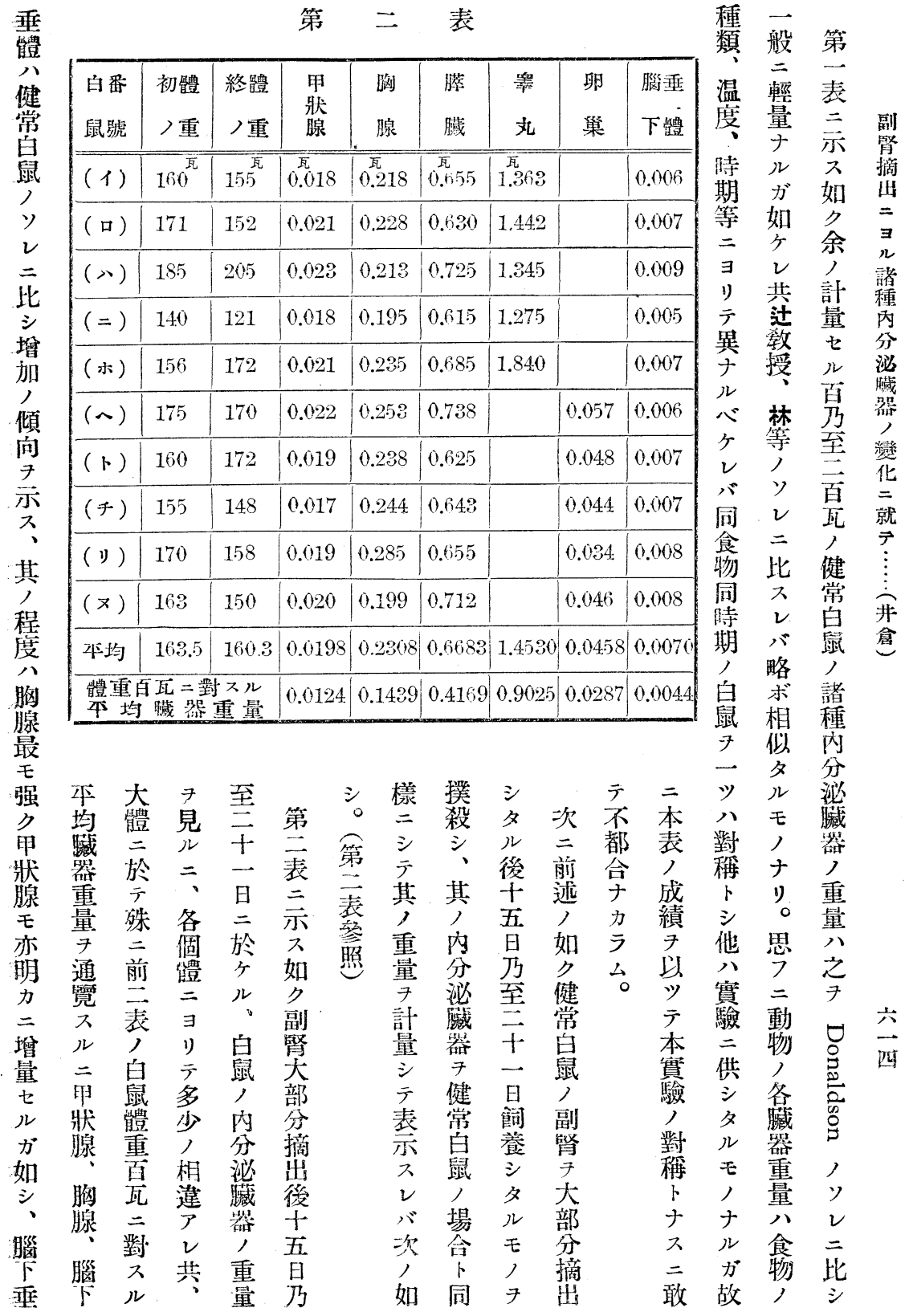




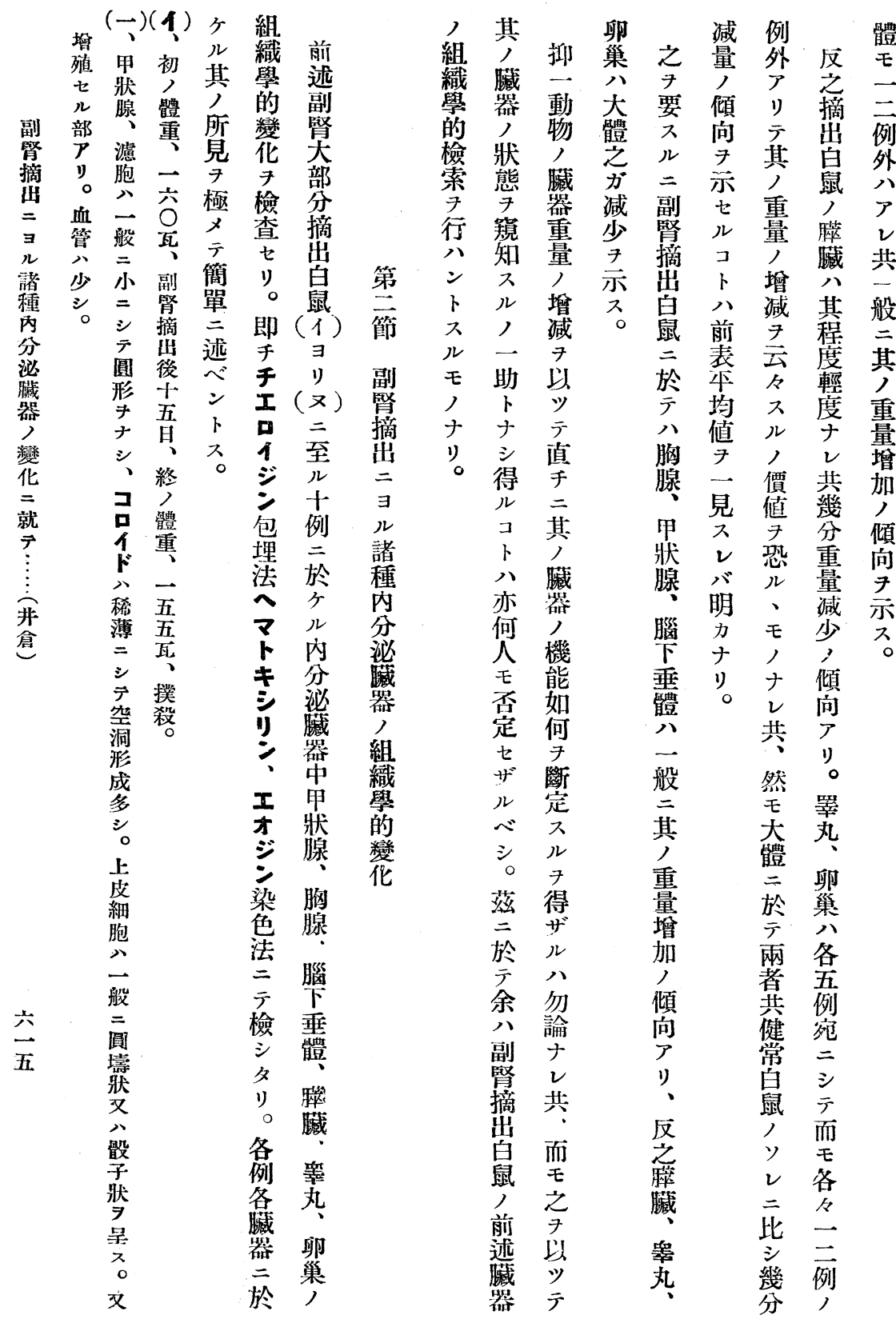




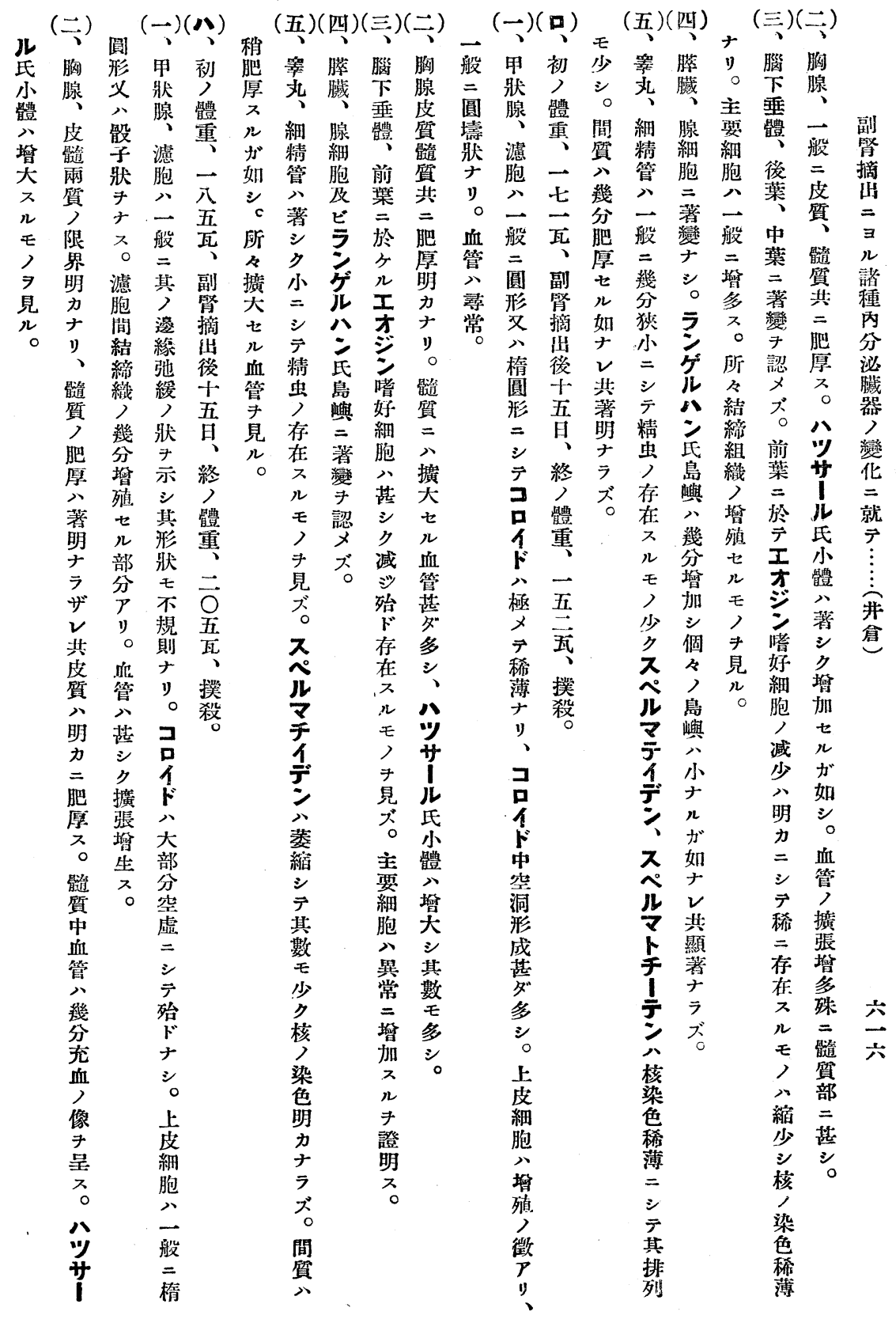




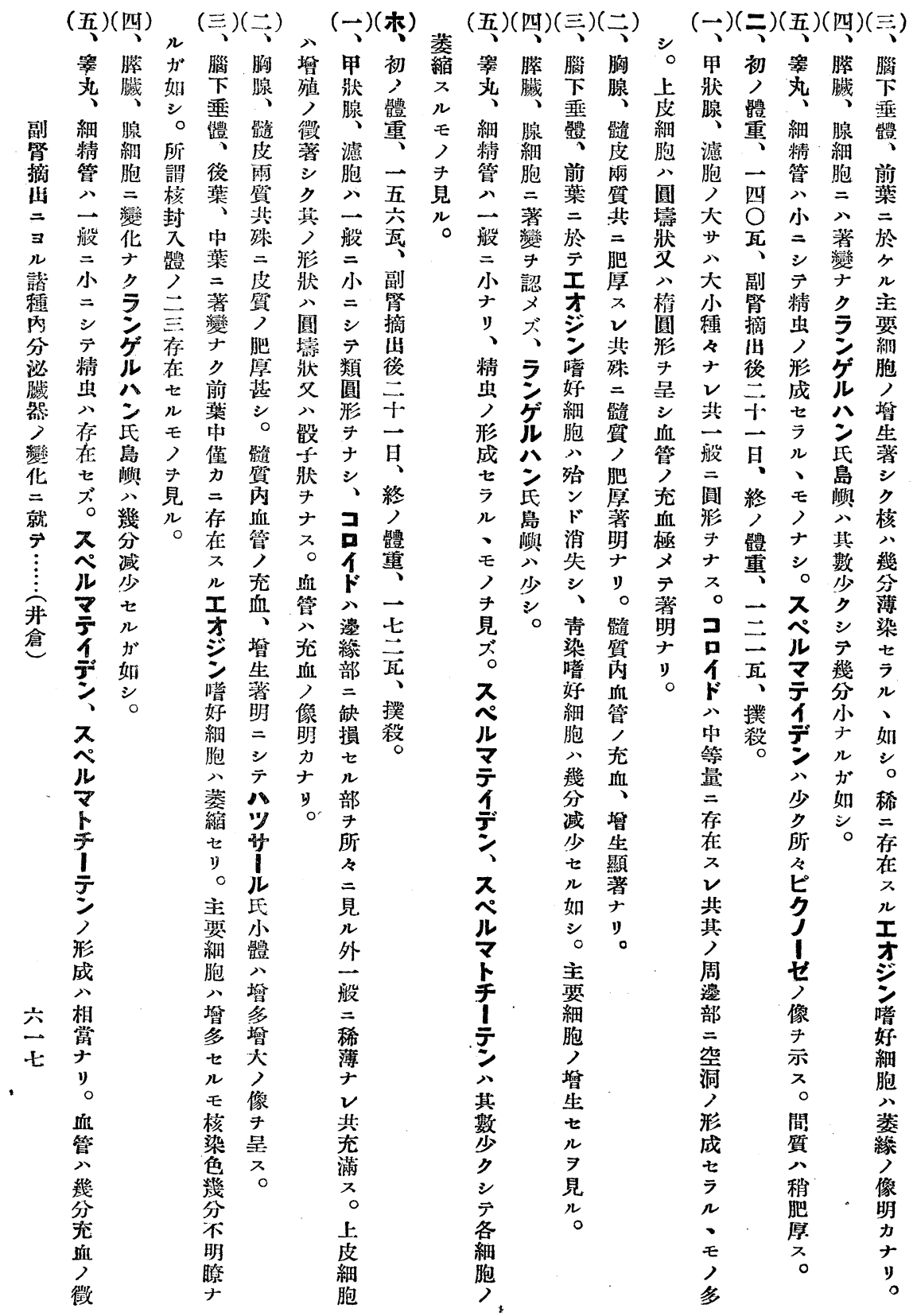




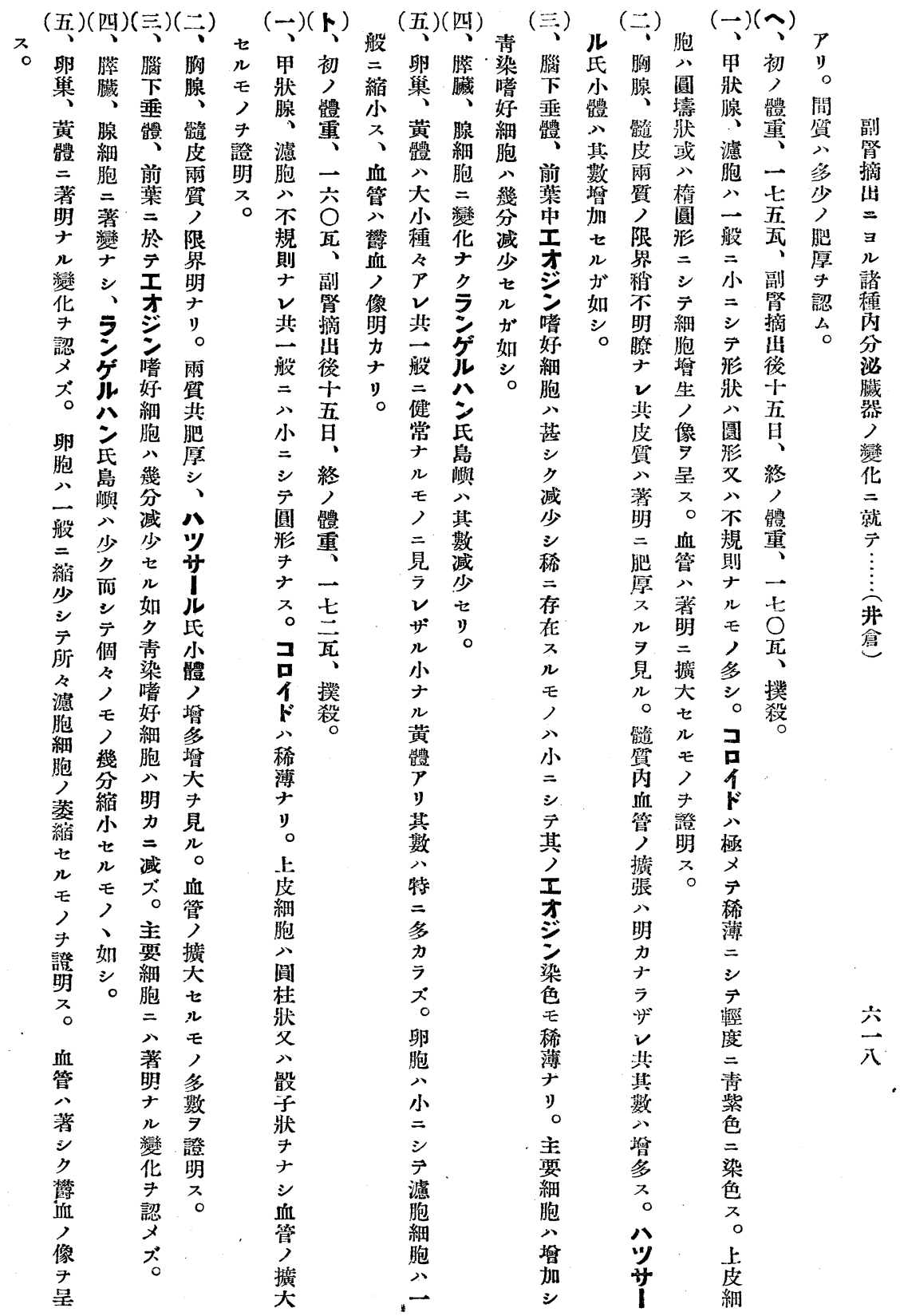




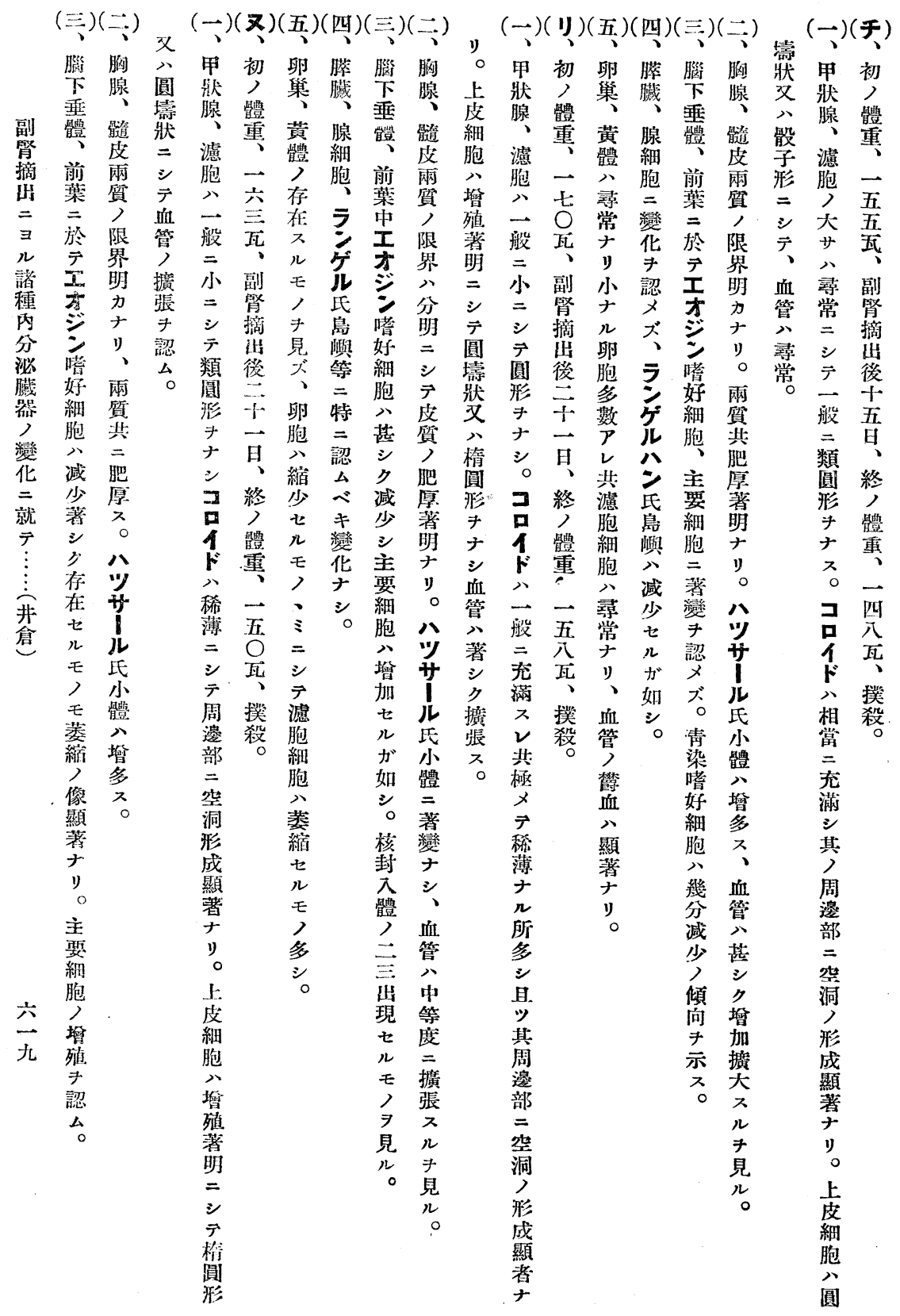




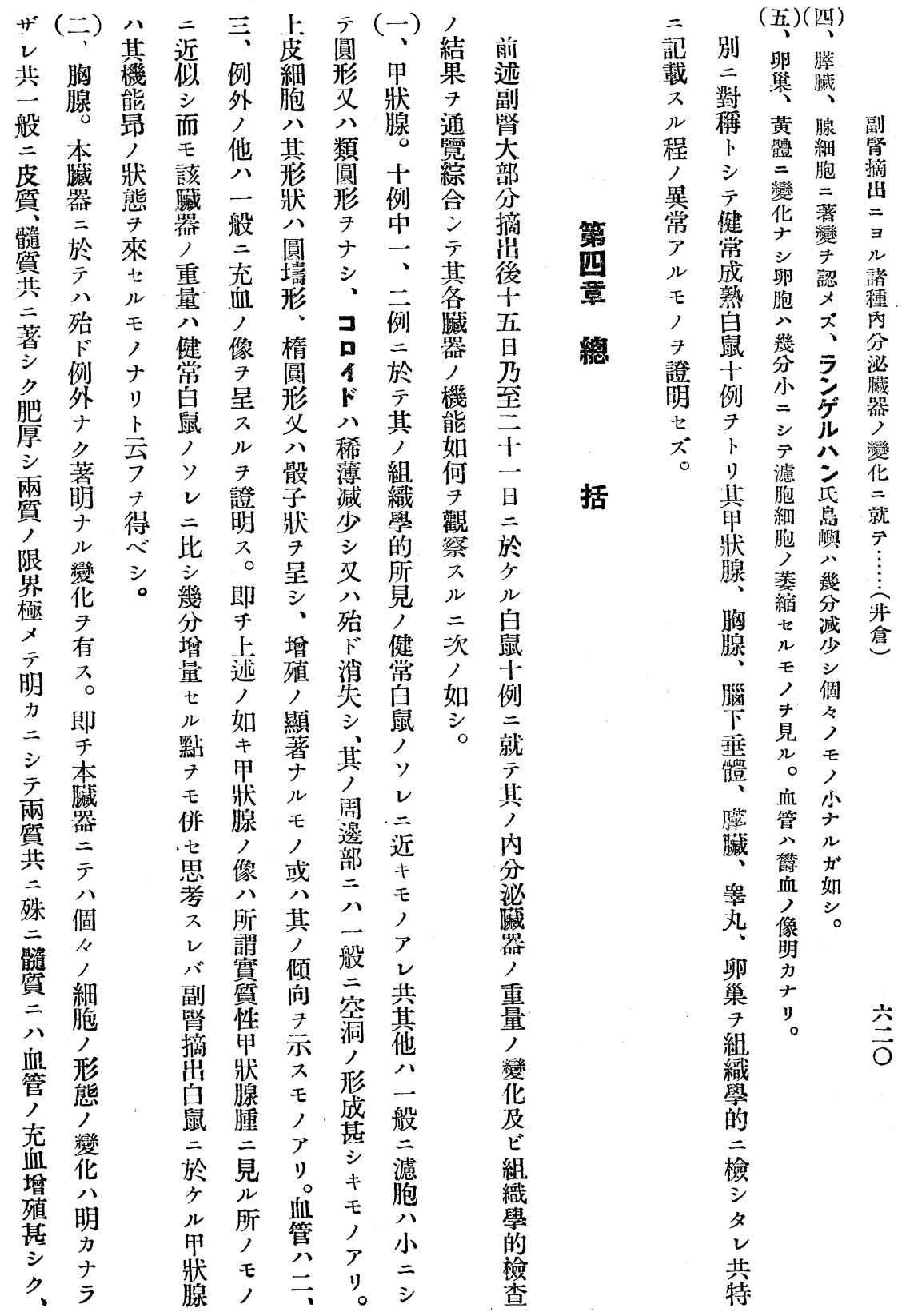




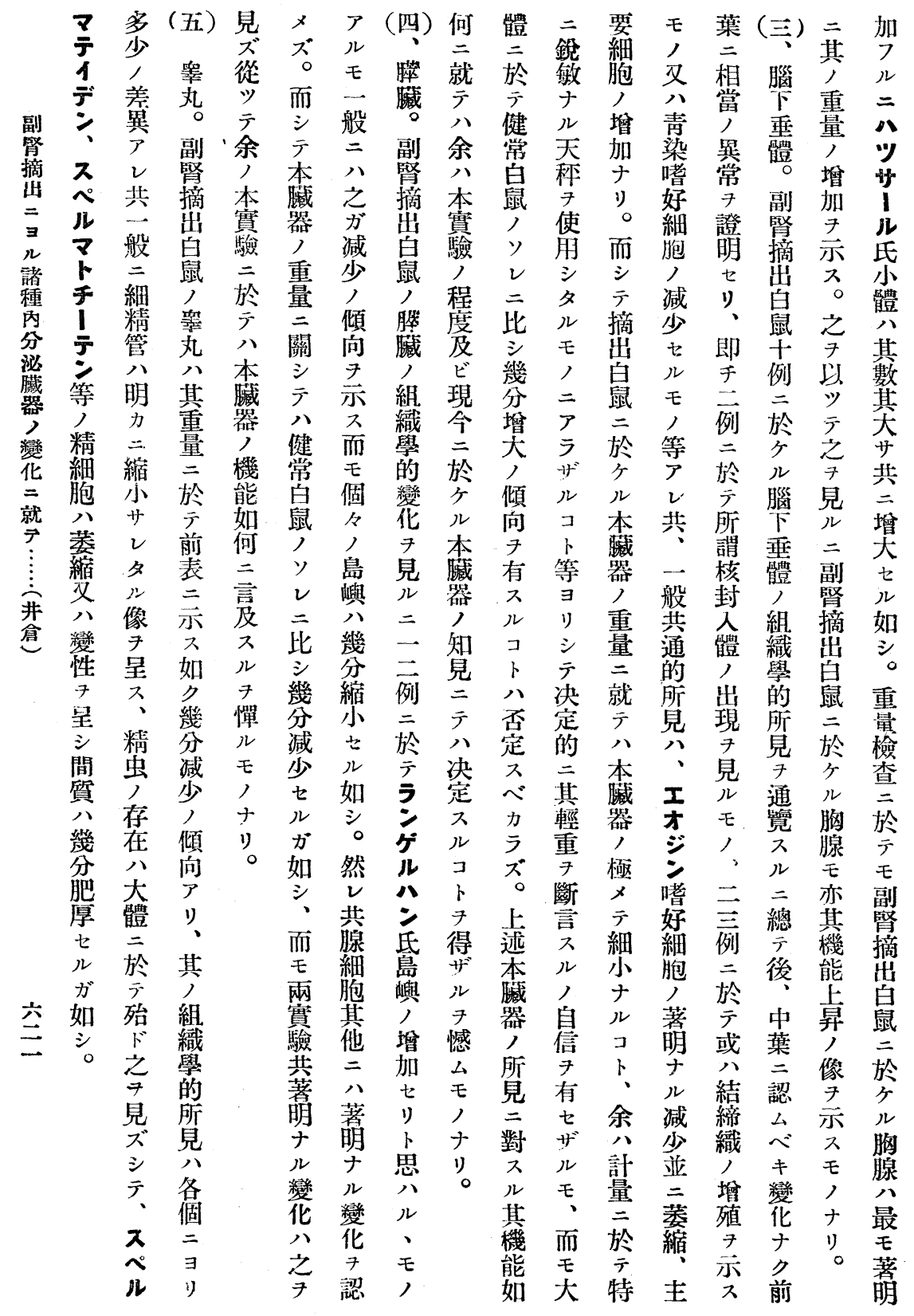




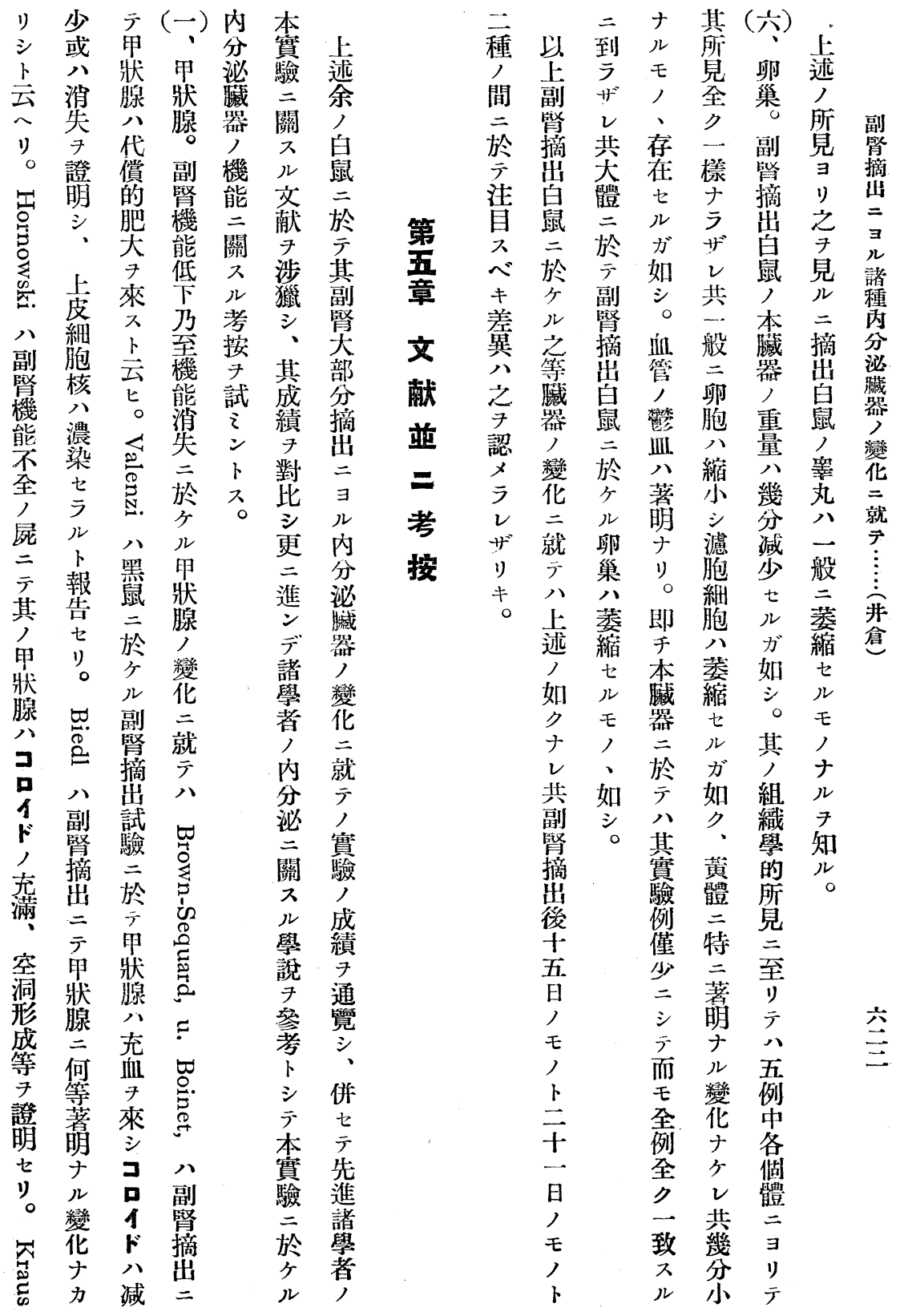




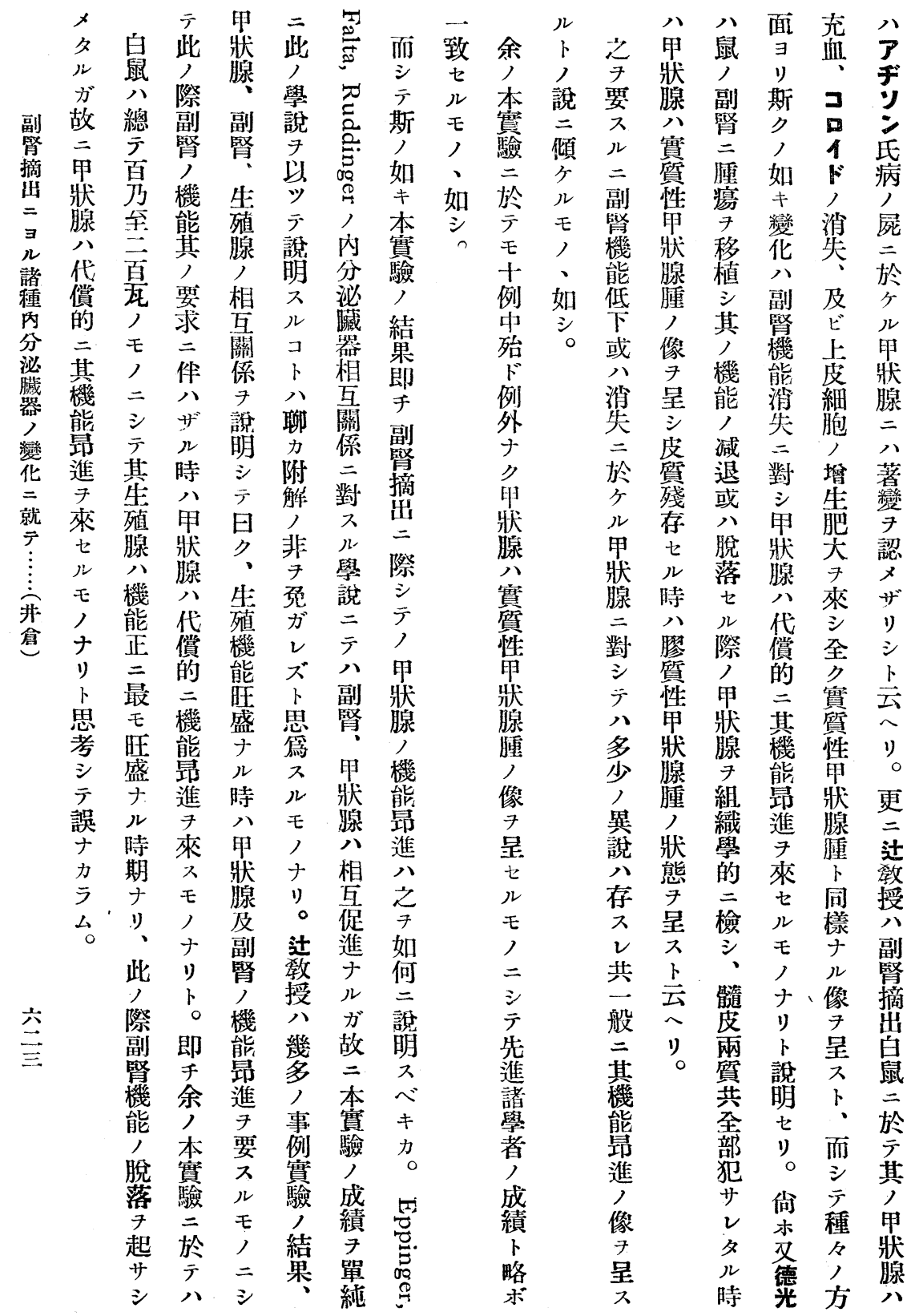




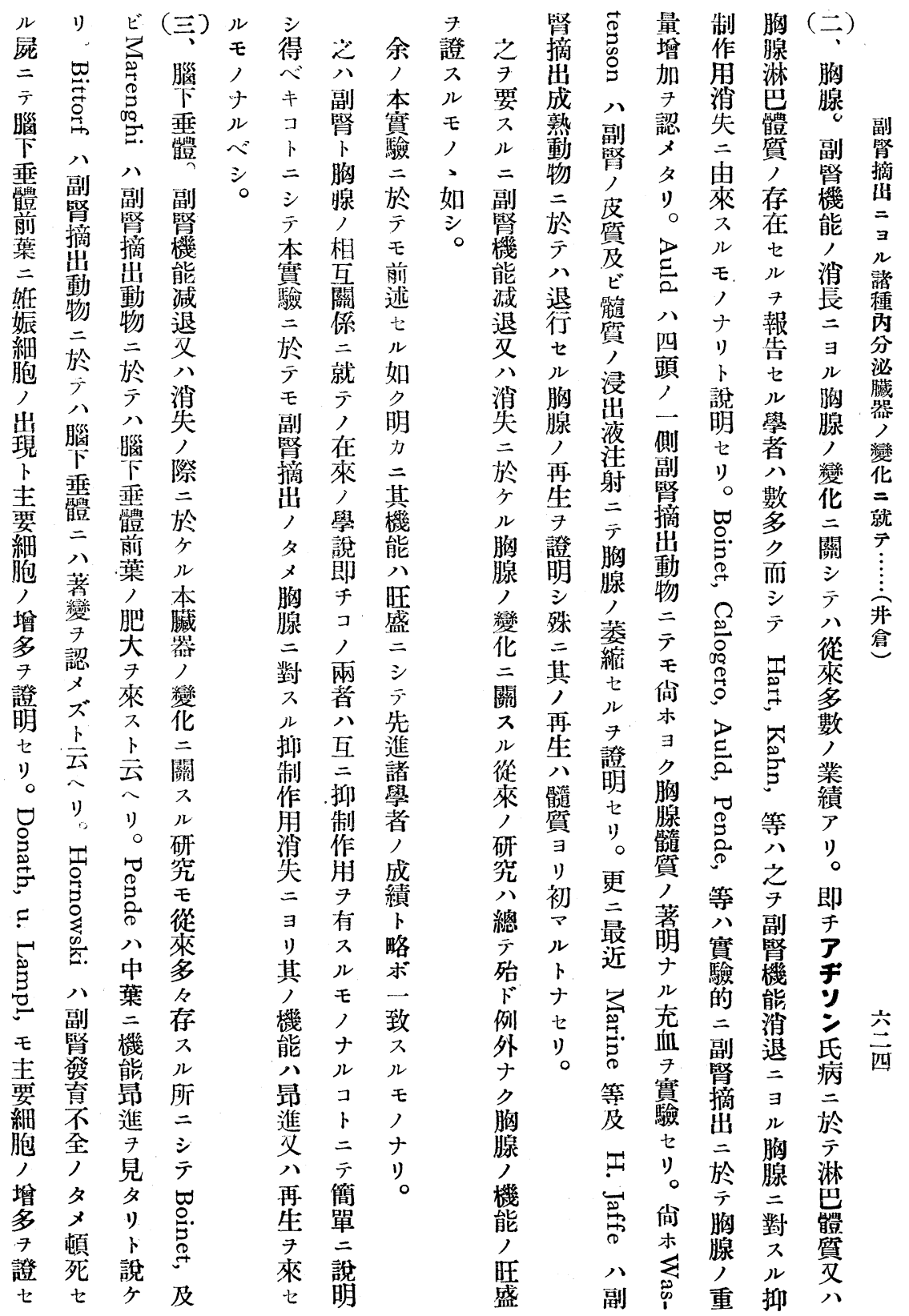




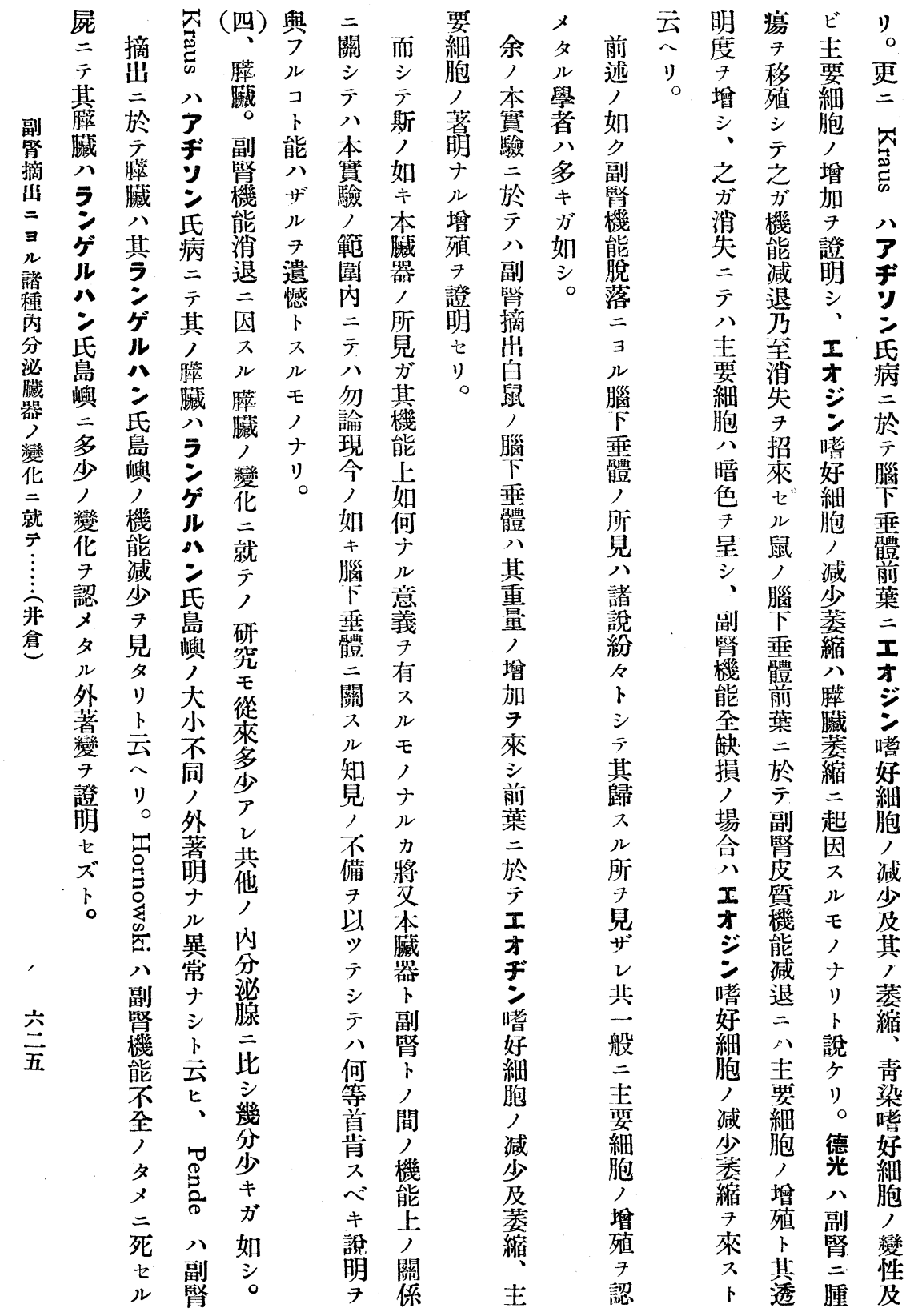




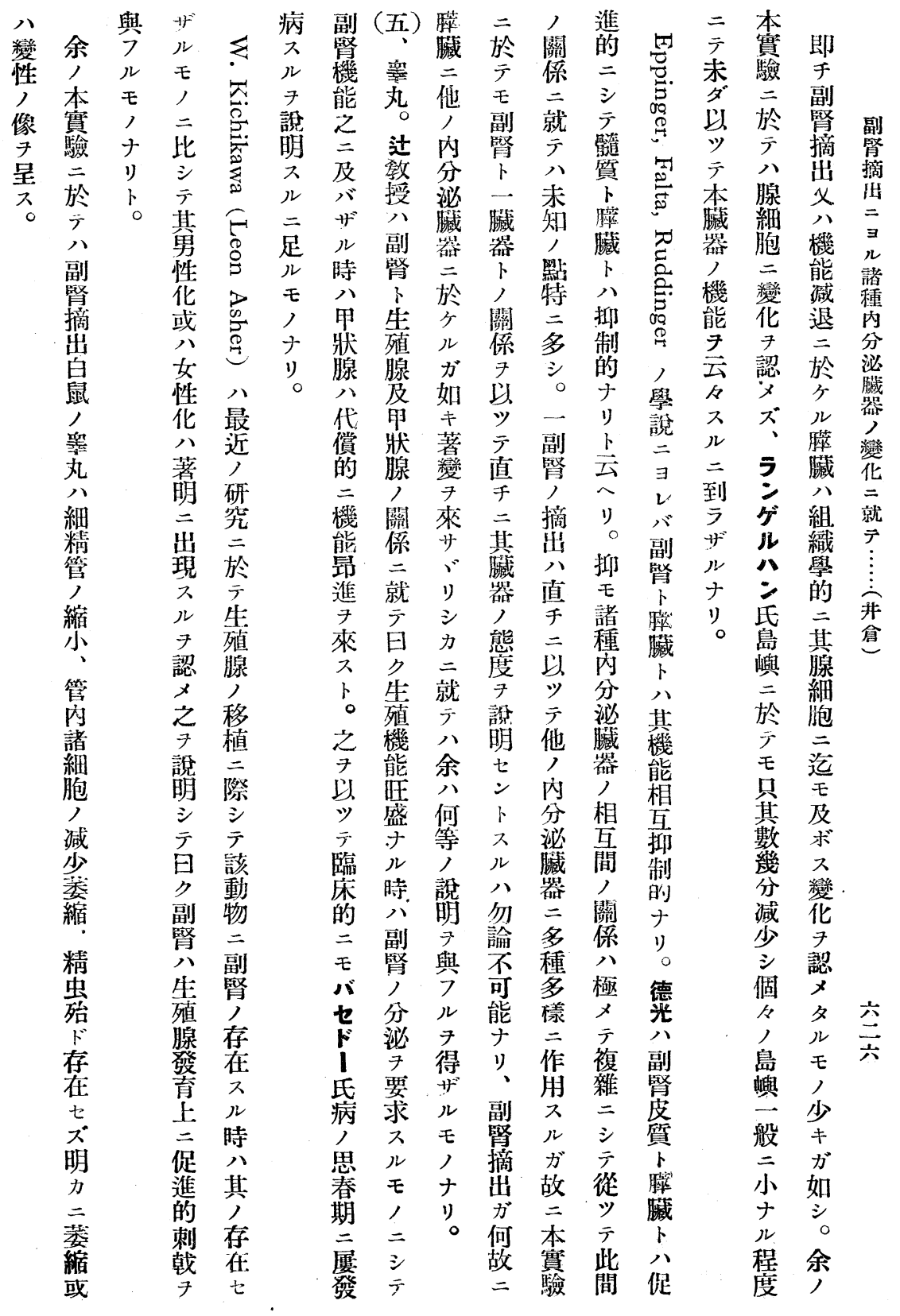




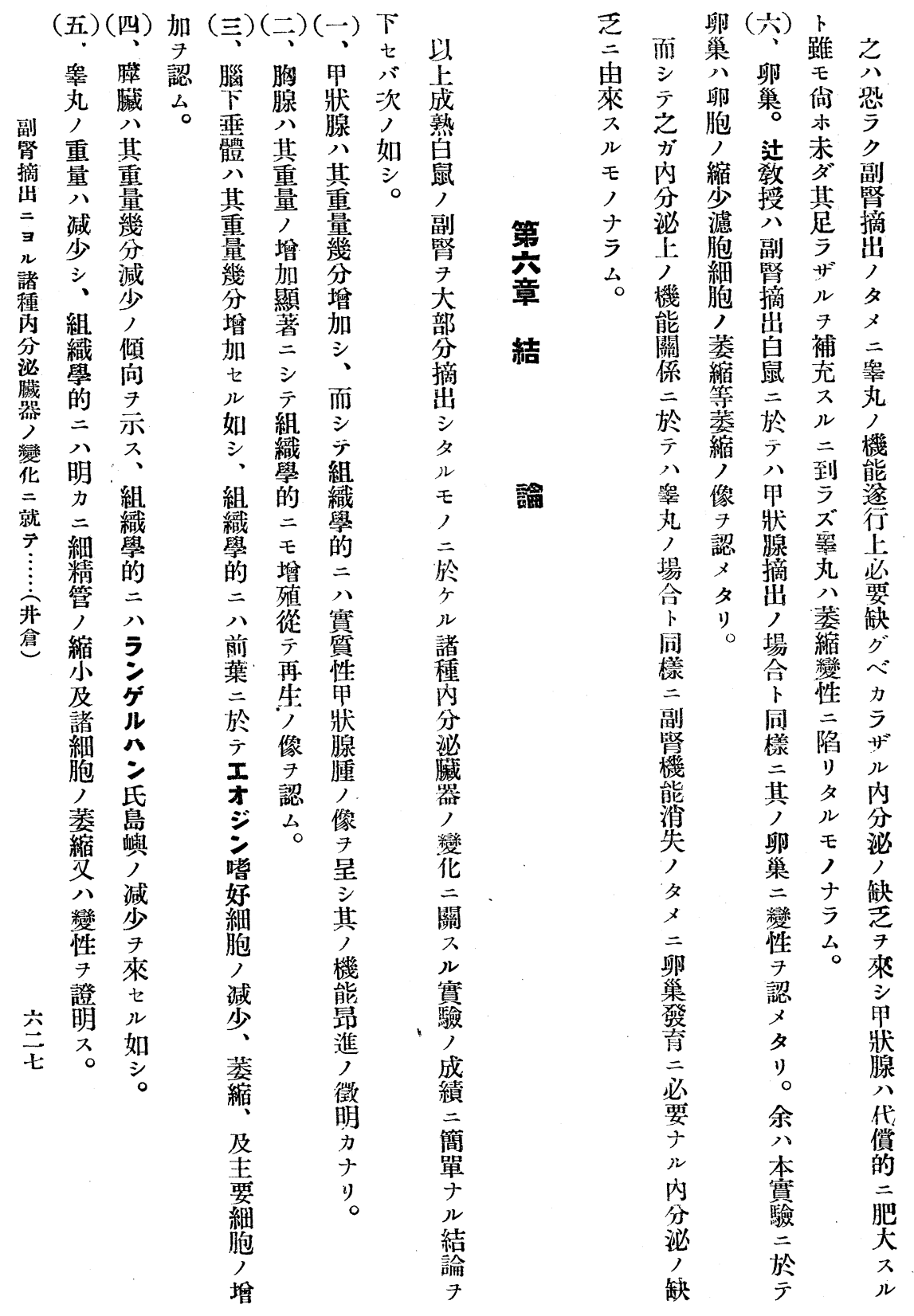




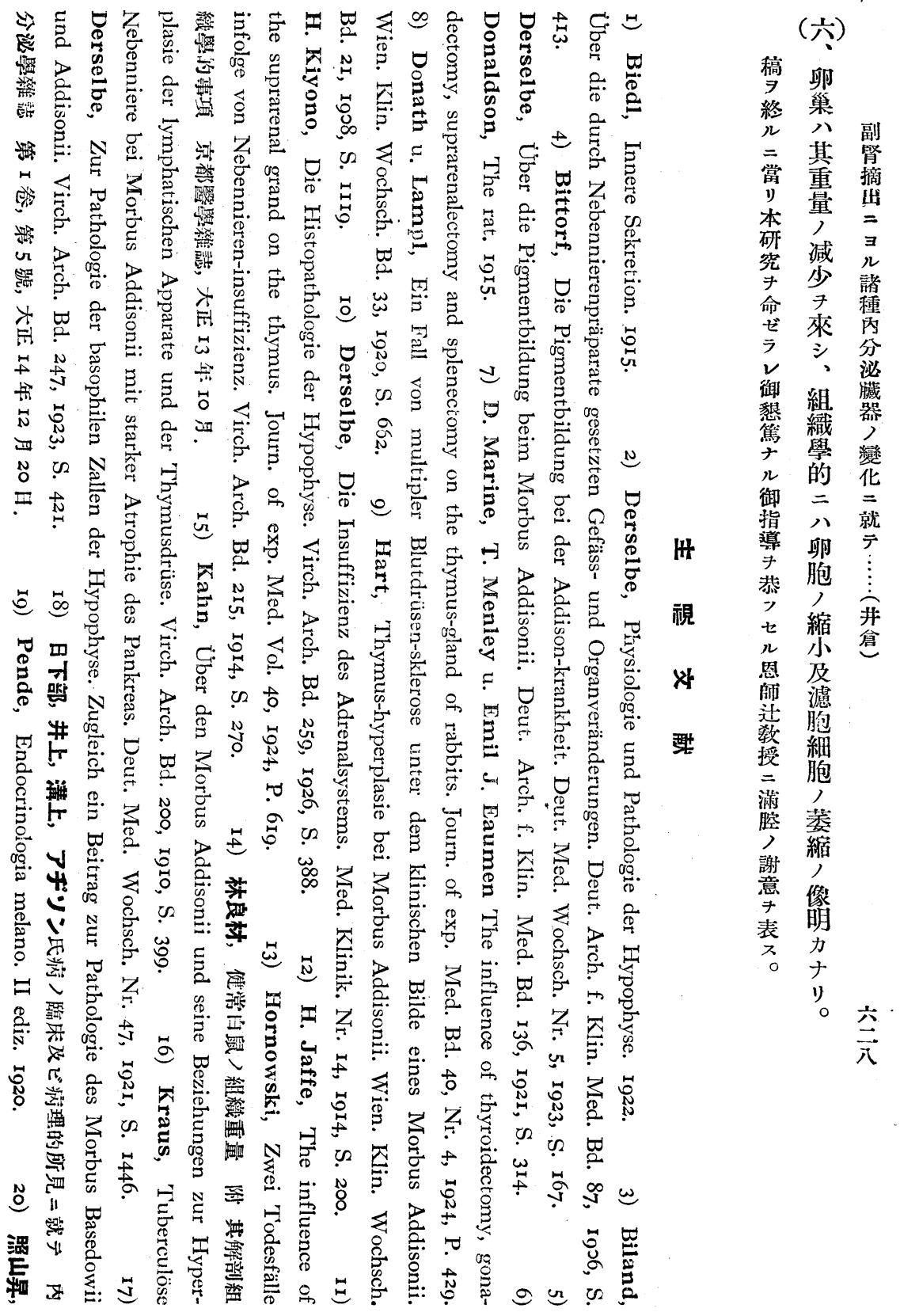



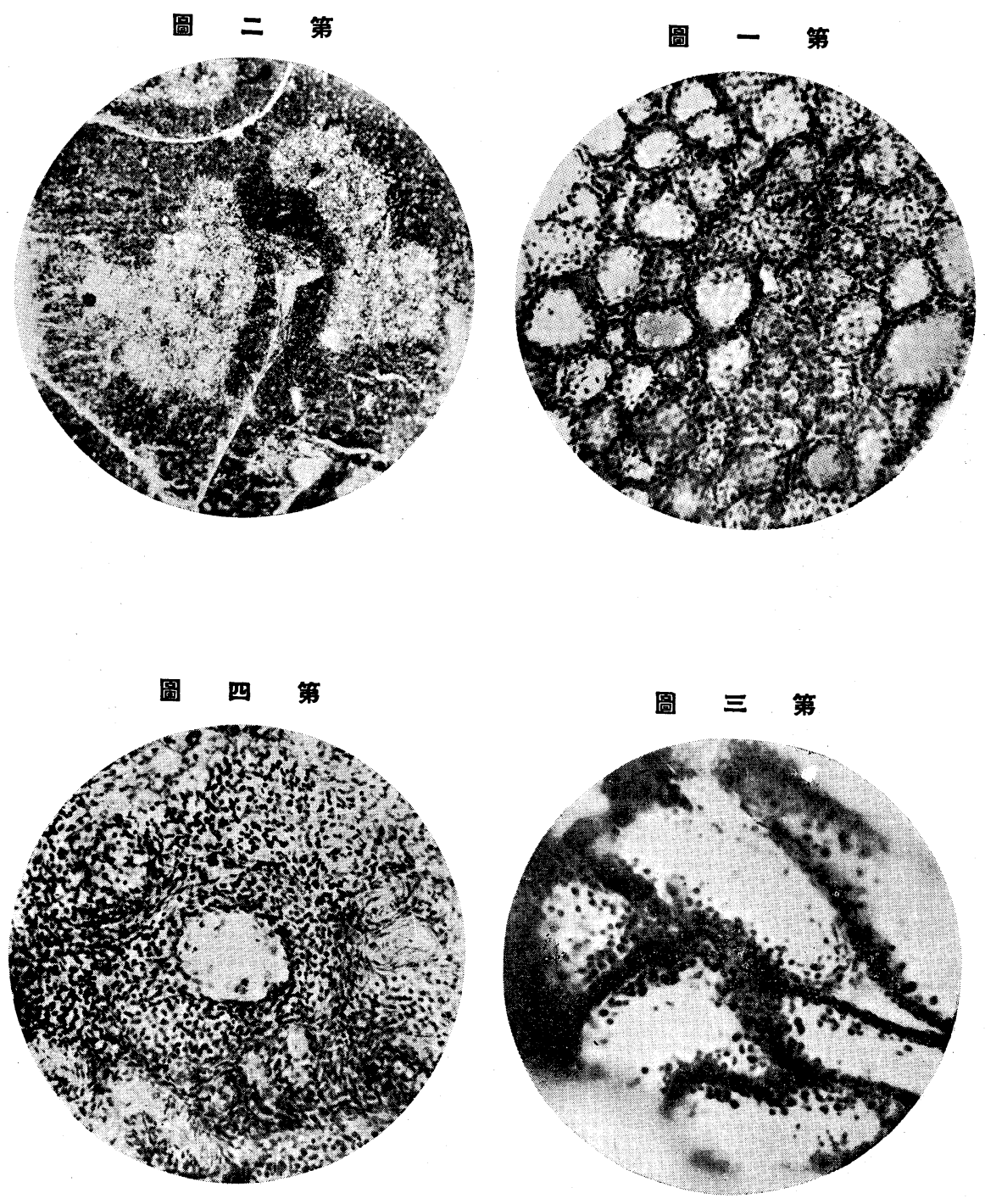
Hauptzellen waren im Anfang etwas vermehrt. Darauf verwandelte sich ein Teil von ihnen in die sogenannten spezifischen Zellen (ähnlich d. sogenannten Schwangerschaftzellen). Anderseits waren eigentümliche Kerneinschlüsse und Kolloidkügelchen zwischen den Drüsenzellen $\mathrm{zu}$ sehen. Im weiteren Verlauf traten allmählich an den chromophilen Zellen degenerative Veränderungen (Schrumpfung der Zellen, Verminderung der Zellzahl u. Vakuolisierung im Protoplasma u. s. w.) auf.

2. Diese Veränderungen im Vorderlappen der Hypophyse waren von der Fütterungsdauer, der Gesamtmenge der gegebenen Schilddrüsensubstanz und weiter vom Alter der Tiere abhängig.

(Autoreferat.)

\section{EXPERIMENTELLE UNTERSUCHUNG ÜBER DIE VERÄNDERUNGEN DER INNERSEKRE- TORISCHEN ORGANE NACH DER NEBENNIERENEXSTIRPATION.}

\section{Von}

Dr. S. Igura.

(Aus der I. Med. Klinik der Kaiserl. Univers. zu Kyoto. Direktor: Prof. Dr. K. Tsuji.)

Man exstirpierte erwachsenen gesundenen Ratten die linke Nebenniere total und die rechte ungefähr $\mathrm{zu} \mathrm{2/3}$, tötete diese Tiere 2-3 Wochen nach der Exstirpation, mass zuerst das Gewicht der verschiedenen innersekretorischen Organe, namentlich der Schild-, Thymus-, Bauchspeicheldrüse, Hypophysis, Hoden und der Eierstöcke, und untersuchte diese Organe histologisch.

Die Resultate waren die folgenden:

I. Das Gewicht der Schilddrüse, der Thymusdrüse und der Hypophyse war gewöhnlich vermehrt, während sich das der Bauch- 
speicheldrüse, der Hoden und der Eierstöcke als ziemlich vermindert erwies.

2. Die Schilddrüse und Thymusdrüse zeigten bei der Mehrzahl der Fälle das Bild der Hyperfunktion.

3. An den Vorderlappen der Hypophyse fanden sich im allgemeinen Verminderung der Eosinophylenzellen und Vermehrung der Hauptzellen.

4. An den Bauchspeicheldrüsen konnte der Verfasser keine nennenswerte histologische Veränderung nachweisen.

5. Die Hoden und die Eierstöcke zeigten das Bild von Atrophie oder Degeneration.

(Autoreferat.)

\section{UEBER DEN EINFLUSS DER VERSCHIEDENEN \\ SUBSTANZEN AUF DEN INSULINBLUT- ZUCKERSPIEGEL (LEICHTMETALL- \\ SALZE, ALKALOIDE U. ALT-TUBERCULIN )}

Von

Dr. Y. Oda.

(Aus der I. Med. Klinik d. Kaiserl. Univ. zu Kyoto in Japan.

Direktor : Prof. Dr. K. Tsuji.)

Mittelst der neuen Bangschen Methode untersuchte der Verfasser den Einfluss der Leichtmetallsalze ( $\mathrm{KCl}, \mathrm{CaCl}_{2}$ u. $\left.\mathrm{MgCl}_{2}\right)$, der Alkaloide (Kokain u. Koffein) und des Alt-Tuberculins auf den Insulinblutzuckerspiegel von reifen männlichen Kaninchen. Der Verfasser gebrauchte nur eine kleine Insulinmenge (per Kilo Körpergew. 1/3I $/ 5$ klin. Einheit) um die toxische Wirkung des Insulins zu umgehen. Von den Metallsalzen wurden 5-3 ccm der 5-20\% igen Lösung intravenös injiziert. Alle Substanzen wurden gleichzeitig mit Insulin injiziert. 